\title{
NEW EXTRACTION PROCESS FOR RECOVERY OF METALS IN GLASS DEPOSITS
}

\author{
Seshadri Seetharaman \\ Olle Grinder* \\ Salt Extraction $A B$ \\ Vällingby, Sweden \\ *Corresponding author: grinder@algonet.se
}

\begin{abstract}
A new process, named salt extraction process, has been developed to enable recovery of metal values from secondary sources e.g. scrap and waste materials such as slag and flue dust. It is also feasible in extracting metals from certain ores that normally are difficult to enrich and process by traditional metallurgy - two examples are nickel and cobalt. The salt extraction process has also been applied in the recovery of metals from silicates including lead from glass wastes.

The process is based on the extraction of metal values from the raw materials into a molten salt bath consisting of $\mathrm{NaCl}, \mathrm{LiCl}$, and $\mathrm{KCl}$ corresponding to the ternary eutectic composition and with $\mathrm{AlCl}_{3}$ dissolved in the salt melt acting as the chlorinating agent. This is followed by the electrolysis of the salt bath in the same reactor. The normal processing temperature is in the range $973 \mathrm{~K}\left(700{ }^{\circ} \mathrm{C}\right)$ to $1173 \mathrm{~K}\left(900{ }^{\circ} \mathrm{C}\right)$. The aluminium chloride in the salt bath reacts with the metals in the fine comminuted raw material and metal ions are formed in the chloride bath. During the electrolysis, the metal ions reach the solid cathode and get deposited in metallic form. Liquid aluminium is used as the anode. Chlorine gas formed at the anode reacts with aluminium forming aluminium chloride in situ, which gets dissolved in the salt melt supplying the required amount of the flux.

The salt extraction process has been used successfully in the extraction of $\mathrm{Cr}$ and $\mathrm{Fe}$ from electric arc furnace (EAF) silicate slag. Experiments have also been carried out in which lead has been recovered with high yield from spent cathode ray tubes. The process was shown to be successful in the extraction of the rare-earth metals neodymium and dysprosium from permanent magnet scrap. The method is a highly promising process route for the recovery of strategic metals. It also has the added important advantage of being environment-friendly, with only small amount recyclable, potentially useful rest products like alumina and silica as with limited energy consumption.
\end{abstract}

\section{KEYWORDS}

Salt melt, extraction, electrolysis, recovery, glass, heavy metals, lead, and aluminium chloride. 


\section{INTRODUCTION}

The Swedish Steel Producers Association (Jernkontoret) has recently finalized an 8 years long, comprehensive research and development programme the Steel Eco-Cycle focused on environmental issues of crucial importance for the steel industry. Several new processes were developed within the frame of this programme enabling more efficient use of energy and raw materials, with special reference to alloying metals in steels and substantially decreased emission of harmful rest products.

One of the new processes developed in this programme, the Salt Extraction Process, has shown to have large potential in recovering of metal values from secondary resources such slag, flue dust, glass and generally from materials in a silicate matrix. The salt extraction process can also be used to recover metal values from scrap and ore concentrates. The Steel Eco-Cycle programme has been very successful and the outcome has been very valuable from an environmental point of view. Further, the concept of the programme was unique on an international scale, enabling a focused as well as an all-embracing treatment of the issue and thus worthy of special presentation.

\section{THE STEEL ECO-CYCLE. ENVIRONMENTAL RESEARCH PROGRAMME FOR THE SWEDISH STEEL INDUSTRY 2004-2012}

The production volume of the Swedish steel industry amounted to 4.5 million tonnes in 2013 and by necessity this consumes large volumes of raw material such as ore, coal, scrap, alloying elements and energy. The objectives of the steel industry since many years are to use the raw materials and energy more efficiently and minimize negative environmental effects such as emission of $\mathrm{CO}_{2}$ and transfer of hazardous elements present in the slag into the ground water from landfills.

With this aim, the Swedish Steel Producers Association (Jernkontoret) has carried out, in cooperation with MISTRA (the Swedish Foundation for Strategic Environmental Research), Swedish Steel Industry, academia and research institutes a very comprehensive national research programme during 8 years i.e. during the period 2004-2012. The total financial contribution was 97 million SEK from MISTRA and 132 from the Swedish steel industry [1].

The overall structure of the programme is shown in Figure 1. One very important concept of The Steel Eco-Cycle environmental research programme was to cover the complete process chain from ore mining to recirculation of scrap and treatment of by-products such as slag and flue dust. It was shown in one project that increased usage of high strength steel in e.g. vehicles has considerable positive effect from an environmental and economical point of view. The application of high strength advanced steels results in decreased weight of the vehicle. This leads directly to decreased fuel consumption and reduced emissions of carbon dioxide.

Several of the projects aimed at;

- recovery of valuable raw materials (alloying metals) from slag and flue dust

- increased yield of raw materials (decreased losses to by-products)

- upgrading scrap

The Salt Extraction Process, which was developed as part of this programme, was one of the processes that focused on the recovery of metal values from slag and dust formed during the processing of steel. 


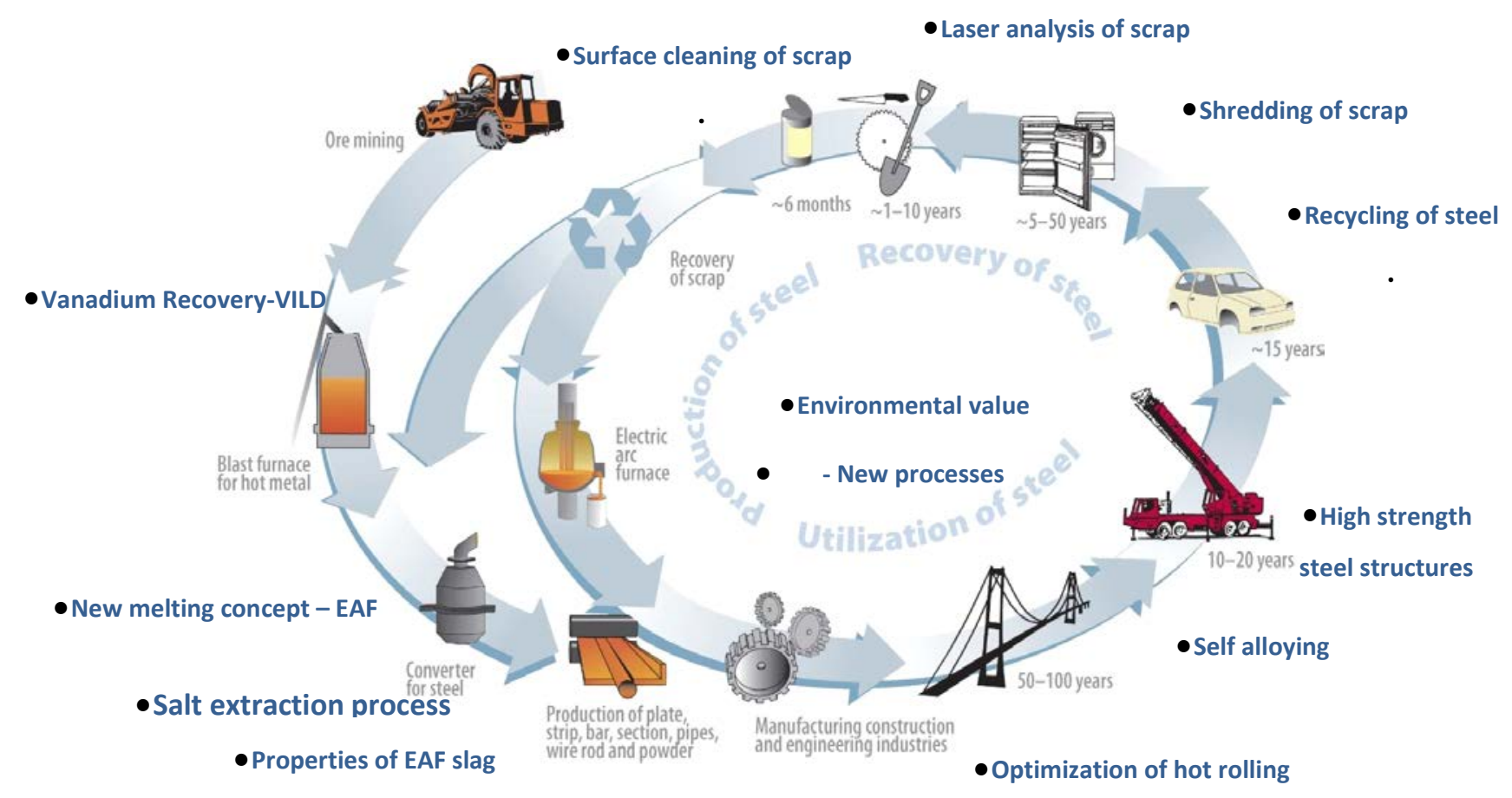

Figure 1. Overall structure of the Steel Eco-Cycle programme including component projects

\section{THE SALT EXTRACTION PROCESS}

This new process enables the recovery of metals from a variety of sources such as metal scrap, silicate-based ores (such as laterites), metallurgical slag and dust. It is highly feasible in many fields of applications. The process is based on chloride metallurgy and is capable of handling many different raw materials.

The salt extraction process is the result of many years of research and development (R\&D) in the fields of chemistry of high-temperature materials, chloride metallurgy, and electrochemical processes. Molten salt electrolysis is used industrially for the reduction and extraction of a number of active elements such as aluminium, magnesium, sodium, and potassium. The metal values in many raw materials, especially in the secondary sources, are often chemically strongly bonded. Chloride melts, having lower melting temperature and being less expensive compared to fluorides, are mostly used in the metal halide extraction processes. The authors discovered that $\mathrm{AlCl}_{3}[3]$ is very powerful in the chlorination of the metals bound to oxide or even silicate matrices and can bring these metals into solution in a molten salt phase comprising salts like $\mathrm{NaCl}, \mathrm{LiCl}$, and $\mathrm{KCl}$.

The chlorination extraction process is combined with electrolysis of the salt melt driving the reaction further so that the metals coming into the salt melt get deposited on the cathode, as shown in Figure 2. This process chain of extraction and electrolysis enables a near complete extraction of the metal values from a given raw material source. 


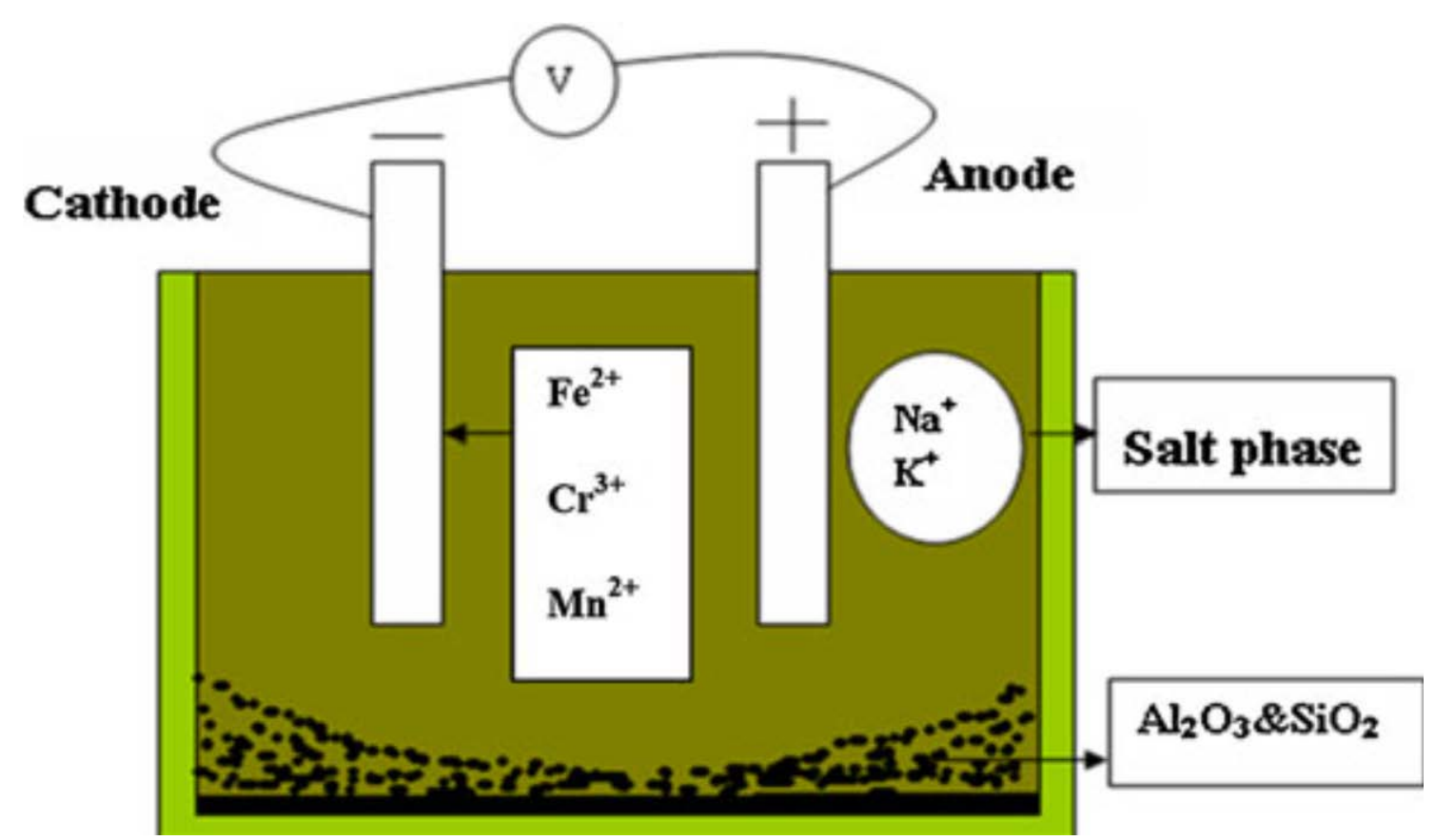

Figure 2. Principle of the Salt Extraction Process (LiCl is added to lower the melting point)

The extraction involves thus two steps, i.e. (I) chlorinated dissolution of the metal and (II) the electrolysis. The chemical reaction involved in the dissolution of an oxide MO being chlorinated by $\mathrm{AlCl}_{3}$ in the temperature range $873-1173 \mathrm{~K}$ can be represented as:

$3 \mathrm{MO}+2 \mathrm{AlCl}_{3}$ (chloride melt) $\rightarrow 3 \mathrm{MCl}_{2}$ (chloride melt) $+\mathrm{Al}_{2} \mathrm{O}_{3}$ (solid)

The ionization of $\mathrm{MCl}_{2}$ in the salt melt can be written as:

$\mathrm{MCl}_{2}$ (chloride melt) $\rightarrow \mathrm{M}^{2+}+2 \mathrm{Cl}^{-}$

The electrochemical reactions involved in the electrolysis are as follows:

Anodic reaction:

$2 \mathrm{Cl}^{-} \rightarrow \mathrm{Cl}_{2}+2 \mathrm{e}^{-}$

Cathodic reaction:

$\mathrm{M}^{2+}+2 \mathrm{e}^{-} \rightarrow 2 \mathrm{M}$

The total cell reaction will thus be:

$\mathrm{M}^{2+}+2 \mathrm{Cl}^{-} \rightarrow \mathrm{M}$ (cathode) $+\mathrm{Cl}_{2}$ (anode)

The electrode reactions presuppose that the reactions 3 and 4 are favoured electrochemically, and other parallel reactions are less prevalent in the electrochemical process. In this respect, it 
is important to check the decomposition potentials of various chlorides of interest from the viewpoint of recovery, see Figure 3.

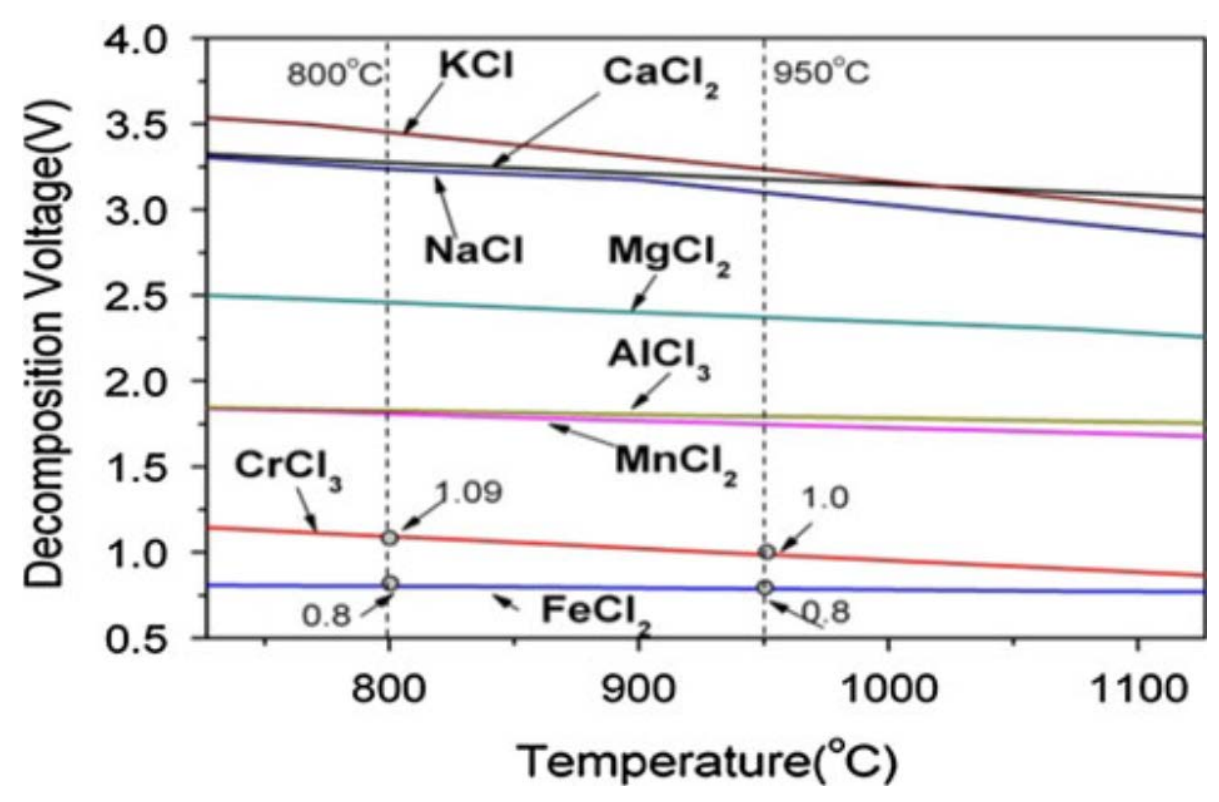

Figure. 3. The decomposition voltages of different metal chlorides during electrolysis.

Thus, simultaneous salt extraction and electrolysis of the molten salt bath enables the extraction of most of the industrial metals including reactive metals like the rare earths and even from strongly bonded matrices. The metal chlorides from the salt bath may also be separated after the extraction by leaching in the aqueous phase or fractional distillation of the vaporized chlorides, see the process flow sheet in Figure 4.

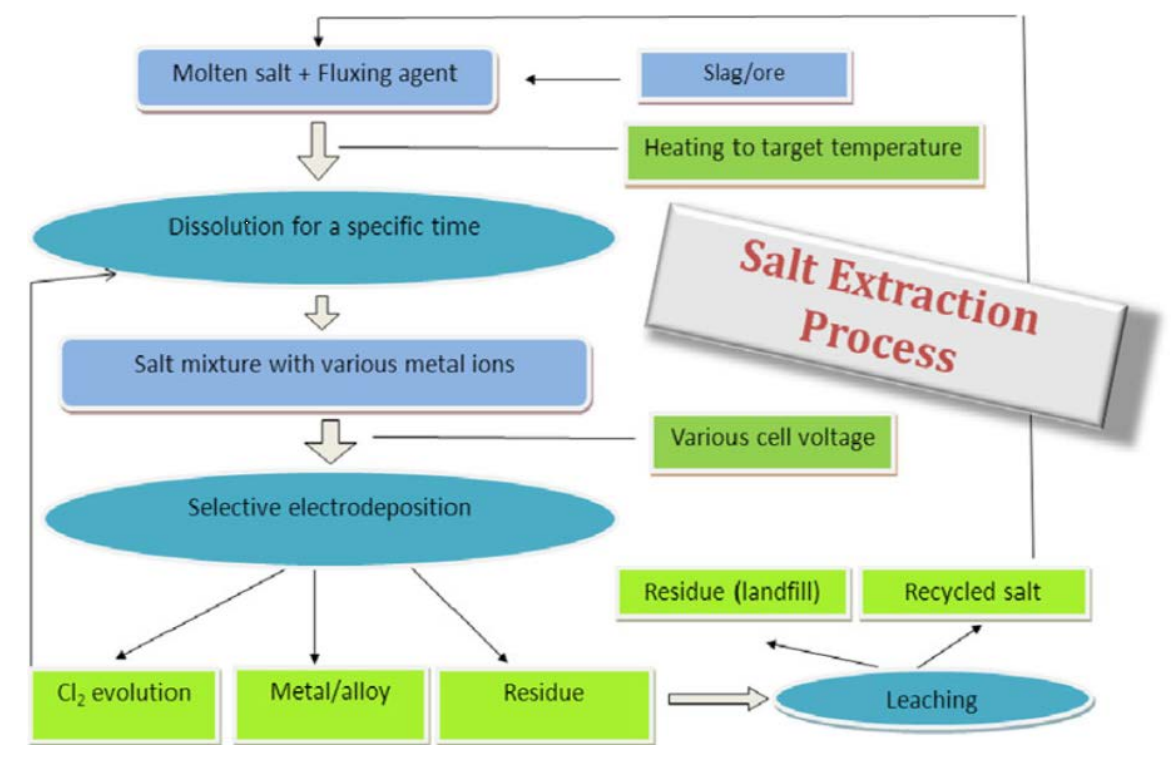

Figure 4. The Salt Extraction Process - flow sheet.

One of the important developments needed to improve the process efficiency is to overcome the loss of $\mathrm{AlCl}_{3}$ to the vapour phase in view of its high vapour pressure at the electrolysis temperature, which is in the range $973 \mathrm{~K}\left(700^{\circ} \mathrm{C}\right)$ to $1173 \mathrm{~K}\left(900^{\circ} \mathrm{C}\right)$. This impediment could be overcome by the use of a liquid aluminium anode. By this unique anode design, $\mathrm{AlCl}_{3}$ is 
generated in the salt melt by the reaction between liquid $\mathrm{Al}$ and $\mathrm{Cl}_{2}$ liberated at the anode enabling the formation of $\mathrm{AlCl}_{3}$ in sufficient amounts in situ, as a function of the cell current passed. This new anode design has now been patented see [4]. The $\mathrm{AlCl}_{3}$ formed dissolves in the chloride melt and chlorinates the metal value. This design has eliminated the emission of chlorine during electrolysis and the gas phase loss of $\mathrm{AlCl}_{3}$. The cost of aluminium chloride is thus minimized due to cheaper scrap aluminium used as the anode, which has a strong impact on the total cost of the process. Furthermore, the process temperature could be lowered by the use of the ternary eutectic salt melt, NaCl-KCl-LiCl.

The applicability of the salt extraction process has been evaluated in the processing and recovery of metal values from primary sources (ore concentrate), secondary sources such as flue dust and slag and also from scrap.

The process was initially used to recover chromium from slag originating from high-alloy steelmaking. Several chromium-containing slags were tried and the results were extremely promising. For example, a slag containing 23 wt. \% FeO and 3.25 wt. $\% \mathrm{Cr}_{2} \mathrm{O}_{3}$ apart from $\mathrm{CaO}, \mathrm{Al}_{2} \mathrm{O}_{3}$, and $\mathrm{SiO}_{2}$ was tried in the process. The cathode deposit consisted of $\mathrm{Fe}$ and $\mathrm{Cr}$ with small amounts of entrapped salts. The recovery levels of these metals were nearly $90 \%$.

The process was also tried in the recovery of copper from chalcopyrite concentrate containing $26 \% \mathrm{Cu}$ in a single step. A high recovery of $\mathrm{Cu}$ as copper deposit at the cathode could be recorded [5]. The deposit is shown in figure 5. By conducting the experiments in reduced oxygen partial pressures, sulphur from the chalcopyrite ore could be recovered in the elemental form as condensate with significant positive impact on the environment.
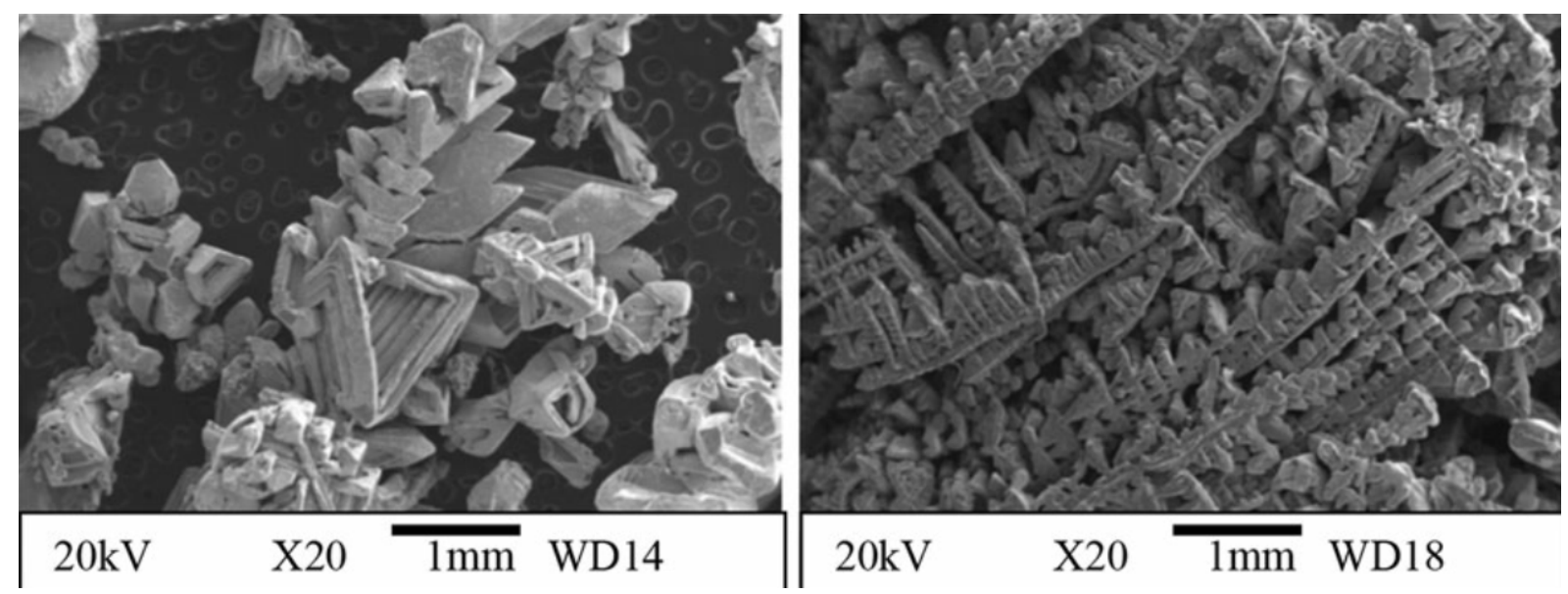

Figure 5. Copper deposits on the cathode obtained by fused salt electrolysis of sulphide concentrate.

\section{EXTRACTIONS OF METALS IN GLASS DEPOSITS}

Can this process be used for the recovery of lead from waste glass materials as for example, the spent cathode ray tubes (CRTs)? The concept for this was jointly initiated by Sweden and Japan with the advent of liquid crystal display (LCD)/light-emitting diode (LED) and plasma flat-screen TV sets, thus rendering CRT tubes containing up to 23 mass\% Pb obsolete. The old cathode ray tube TVs had to be safely discarded and cannot just be dumped as landfill. Furthermore, export of CRTs is not allowed. Some lead smelters currently handle CRTs for lead recovery which may not be economically attractive. The newly invented Salt Extraction 
process was considered to offer an alternative route to recover $\mathrm{Pb}$ from such spent CRTs. Initial trials in Sweden showed that, with spent CRT glass showed [6] that, even without the electrolysis step, the recovery of lead in the salt melt was more than $97 \%$, which can be improved by electrolysis. These results suggest that the method can be successfully applied to the recovery of harmful metals from dumps of waste glass in Sweden and elsewhere. Investigations are currently underway towards a total recovery of lead and other harmful metals from such silicate materials, which pose one of the serious environmental challenges in modern technological development.

\section{SUMMARY}

The salt extraction process, developed as a part of the Eco-Steel programme of the Swedish Steel Producers Association has shown very promising results in the extraction of metal values from secondary sources. The method utilizes the combined extraction of metals into a chloride bath and electrolysis of the salt bath in the temperature range $973-1173 \mathrm{~K}$. The cell design has the unique feature of having liquid aluminium as the anode which generates the chlorinating flux $\mathrm{AlCl}_{3}$ in situ and eliminates the risk of chlorine emission.

The process has been successfully applied to the extraction of $\mathrm{Cr}$ and $\mathrm{Fe}$ from slags, $\mathrm{Cu}$ from concentrates, rare earth metals from magnetic scrap and Pb from CRT glass. The method is a very promising route for the recovery of environmentally harmful metals from waste glass dumps.

\section{ACKNOWLEDGEMENTS}

The authors express their sincere gratitude to Swedish Steel Producers Association for their support in developing the process. Our special thanks are due to Mr. Göran Andersson (Jernkontoret) for valuable discussions and continuous support.

\section{REFERENCES}

[1] The Steel Eco-Cycle. Environmental Research Programme. Jernkontoret Research. Evaluation Report D851. www.stalkretsloppet.se.

[2] Abbasalizadeh A., Seetharaman S., Teng L., Seetharaman S., Grinder O., Izumi Y. and Barati M.; Highlights of the Salt Extraction Process. JOM, 2013, Vol. 65:11 pp. 1552-1558.

[3] Seetharaman S. \& Grinder O.: A Process for Chlorinating Resources Containing Recoverable Metals. U.S. patent 8,470,271 B2.

[4] Teng L., Seetharaman S \& Seetharaman S.: A Process for Recovering Metals and an Electrolytic Apparatus for Performing the Process. EP2744927 (A1).

[5] Ge X.L. \& Seetharaman S.: The Salt Extraction Process: a Novel Route for Metal Extraction Part 2 - Cu/Fe extraction from copper oxide and sulphides. Trans. Inst. Min. Metall. C. Min. Proc. Extr. Metall. 2010, Vol.119:2 pp. 93-100.

[6] Y. Tanaka, M. Sc. Thesis work, Royal Inst. of Technol., Stockholm, Sweden, 2012. 